\title{
INÉS ARREDONDO: UNA ESCRITORA EJEMPLAR
}

Claudia Albarrán*

RESUMEN: Inés Arredondo perteneció a la llamada Generación de Medio Siglo, particularmente, al grupo de intelectuales y artistas que fundaron e impulsaron las actividades culturales de la Casa del Lago durante los años sesenta. El artículo es una semblanza que da cuenta tanto de los hechos más importantes que marcaron la vida y la trayectoria intelectual de Inés Arredondo, como de los rasgos particulares (estéticos) que definen la obra narrativa de esta escritora excepcional.

$$
\text { sose }
$$

ABSTRACT: Inés Arredondo belonged to the so-called Mid-Century Generation, namely a group of intellectuals and artists that established and promoted Casa del Lago's cultural activities in the Sixties. This article gives an account of the important events and intellectual journey that shaped the writer's life particularly the esthetic characteristics that shaped the narrative work of this exceptional writer.

PALABRAS ClAVE: Inés Arredondo, literatura mexicana, Generación de Medio Siglo, Casa del Lago, cuento.

KEYWORDS: Inés Arredondo, Mexican Literature, Mid-Century Generation, Casa del Lago, short story.

RECEPCIÓN: 24 de abril de 2008.

APROBACIÓN: 22 de mayo de 2008.

* Departamento Académico de Lenguas, ITAM. 
CITAM Derechos Reservados.

La reproducción total o parcial de este artículo se podrá hacer si el ITAM otorga la autorización previamente por escrito. 


\section{INÉS ARREDONDO: UNA ESCRITORA EJEMPLAR*}

\section{Borró su segundo nombre (Amelia)} y tachó su primer apellido (Camelo) para honrar al abuelo, prolongando, con ello, la ascendencia de su madre, que era hija única. Cumplió con honores la educación primaria, arrebatándoles a sus compañeras del colegio Montferrant todas las medallas y los méritos académicos. Declamó y actuó desde niña en los eventos más prestigiosos de Sinaloa, memorizando poemas completos que salpimentó con ademanes y gestos teatrales que repasaba día a día bajo la mirada vigilante de su madre. Renegó del bullicio de su casa, rebosante de hermanos, porque interrumpían su silencio y le impedían concentrarse en la lectura. Encontró refugio en Eldorado, una hacienda azucarera venida a menos, pero en la que solía pasar las vacaciones, cobijada por las historias de apogeo que su abuelo recreaba por las noches y que ella mitificó en sus cuentos como una única manera, entre otras posibles, de reinventar su historia y trazar las líneas de su destino personal.

Asistió secretamente a la Universidad Autónoma de Sinaloa mientras sus amigas intercambiaban besos y raspados con los adolescentes de Culiacán. Ante la oposición de sus padres de que viviera lejos de casa, encontró el apoyo firme y el financiamiento seguro de Papá Pancho, el abuelo materno, para vivir en Guadalajara mientras continuaba sus estudios. En las casas de huéspedes que ocupó durante los años en los que estudió la preparatoria, olió la soledad y comprendió

* Texto leído en el Homenaje a Inés Arredondo a 80 años de su natalicio, que se llevó a cabo el 27 de abril del 2008 en la sala Manuel M. Ponce del Palacio de Bellas Artes. 
que había un mundo más doloroso, pero también más profundo y verdadero, que contrastaba con la realidad fingida que había comenzado a intuir durante su infancia, cuando devoraba la serie de volúmenes de la colección Austral.

Con el piloto Juan Manuel López sostuvo una larga relación y, por primera vez, supo que podía ser amada, adorada; que dejarse querer no es un pecado, aunque una corra el riesgo de volverse diosa. Recorrió las calles de Culiacán de la mano de ese novio, orgullosamente enfundada en un traje de piloto: cabeza erguida, mirada dirigida hacia el cielo, lentes de aviador colocados sobre la frente, casaca condecorada en el pecho... Pero no estaba satisfecha.

Dudó. Lloró. Se rebeló contra las enseñanzas de las monjas del colegio y dejó de asistir a la misa diaria. Rumió calladamente sus inseguridades. Perdió la timidez y la vergüenza, y de nuevo consiguió que se cumpliera su deseo de vivir y estudiar fuera de Culiacán para radicar en la ciudad de México. Ingresó a la licenciatura de Filosofía en la UNAM, en 1947; leyó a los existencialistas y convivió con los exiliados españoles. Un fuerte conflicto espiritual la empujó a abandonar la filosofía y a buscar otros caminos menos sinuosos, como el arte dramático, primero, y la biblioteconomía, después. Continuó tratando

116 de espantar viejos miedos, antiguos fantasmas éticos y morales, e, imposibilitada para seguir confiando en los valores tradicionales, asistió decididamente y con fanática regularidad a exposiciones de pintura, a conciertos y a charlas sobre arte y literatura. Se inscribió, al fin, a la licenciatura en Letras Hispánicas, en donde conoció a sus mejores amigos, también escritores, que más tarde integrarían la llamada generación del Medio Siglo, también llamado grupo de la Casa del Lago: Juan García Ponce, Huberto Batis, Juan Vicente Melo y José de la Colina, entre otros, que la admiraron por su inteligencia, por su mirada profunda y por sus frondosas piernas, desde luego.

Al cabo de un tiempo, perdió la fe, pero encontró la compañía del poeta Tomás Segovia, quien se volvió su interlocutor, su promotor literario y su primer esposo. Con él, tuvo cuatro hijos: Inés, José, Ana y Francisco. 
Comenzó a escribir azarosamente, tras la muerte de su segundo hijo, recién nacido. Ella lo contó así:

Creo que puedo precisar más o menos el momento en que comencé a escribir: mi segundo hijo había muerto, pequeñito, y por más que esto entristeciera a todos, mi dolor era mío únicamente. Sólo yo sentía mis entrañas vacías, únicamente a mí me chorreaba la leche de los pechos repletos de ella. Mi estado psicológico no era normal: entre el mundo y yo había como un cristal que apenas me permitía hacer las cosas más rutinarias y atender, como de muy lejos, a mi pequeña hija Inés. Era algo más grave que el dolor y el estupor del primer momento. Yo estaba francamente mal. Para abstraerme, que no para distraerme, me puse a traducir, con mucha dificultad, creo que un cuento de Flaubert, y de pronto me encontré a mí misma escribiendo otra cosa que no tenía que ver con la traducción. ${ }^{1}$

Publicó sus primeros cuentos y reseñas en la Revista de la Universidad, en la Revista Mexicana de Literatura -de la que se volvió asidua colaboradora-, en La Cultura en México y en la Revista de Bellas Artes. Obtuvo una beca del Centro Mexicano de Escritores de 1961 a 1962, otra de la Fairfield Foundation en Nueva York (en 1962) y vivió un tiempo en Montevideo, en un intento por superar sus problemas matrimoniales. Regresó a México ya separada, con los tres niños a cuestas, y tuvo que emplearse en infinidad de trabajos menores que apenas le dejaban tiempo para escribir. Se casó por segunda vez en 1972 con el médico Carlos Ruiz, quien desde entonces y hasta su muerte sería su guardián de cabecera.

A lo largo de su vida, Inés sufrió agudas crisis que la llevaron dos veces al psiquiátrico, además de siete cirugías: cinco de columna, otra provocada por una oclusión intestinal y una, más leve, a causa de un problema ocular. Pasó sus últimos años recluida, deambulando entre la habitación y la sala de su departamento, oscilando entre la lucidez y la confusión, siempre sostenida por analgésicos y por antidepresivos. Murió en la ciudad de México un 2 de noviembre de 1989, tibia

\footnotetext{
${ }^{1}$ Cfr., Inés Arredondo, “La cocina del escritor”, Sábado, 29 de marzo, 1997, p. 1.
} 
y silenciosa, recostada en su cama, mientras miraba la película del canal 11 en la televisión.

Publicó tres libros de cuentos - La señal, 1965; Río subterráneo, 1979, con el que obtuvo el Premio Xavier Virraurrutia, y Los espejos, 1988-, el relato para niños titulado Historia verdadera de una princesa (1984), un conjunto de textos autobiográficos, una serie de reseñas sobre libros, teatro y revistas literarias, y un puñado de ensayos; uno de ellos, extenso y brillante, dedicado al poeta Jorge Cuesta, cuya vida y obra le provocaba una misteriosa curiosidad. Trabajó cada uno de sus cuentos palabra por palabra, línea tras línea, con el cuidado y la humildad de un artesano. Los tachó, los reescribió, los dejó reposar meses, incluso años, para volver a leerlos, a tacharlos, a reescribirlos todas las veces que consideró necesarias, hurgando siempre en el significado de las palabras para obligarlas a decir lo que no estaban acostumbradas a decir.

En los años más duros, cuando su cuerpo se volvió casi un estorbo, dejó la máquina de escribir y se aferró a una tablilla de madera sobre la que colocaba las hojas de papel revolución en las que garabateaba pausadamente las historias de sus relatos, las frases de sus reseñas o de sus ensayos, que Carlos Ruiz, Ana su hija o alguna amiga transcribían más tarde para que ella pudiera leerlas y enmendarlas, leerlas y enmendarlas, leerlas y enmendarlas, en un ejercicio permanente, de obsesiva pulcritud y perfección.

Abordó temas prohibidos para las letras mexicanas de entonces, como el incesto, el aborto, la homosexualidad, la demencia, el amor destructivo de la pasión, el triángulo amoroso, el vampirismo, el voyeurismo, la contaminación por el mal, la orfandad originaria y el auto-sacrificio, sobre todo. Entre la somnolencia y los escasos ratos de vigilia que marcaron varios momentos de su vida, siempre consiguió reponerse, desplegando un mundo adolorido que no le era ajeno; un universo de seres solitarios, desprotegidos, descascarados, despostillados, enfermos, mutilados, maltrechos, que pululan - a veces puros, a veces contaminados; a veces santificados, a veces endemoniados-, por el mapa de ese Eldorado que le sirvió de escenario para sus historias y que ella construyó árbol por árbol, sombra tras sombra, 
camino por camino, sabiéndose creadora de un nuevo, aunque terrible Edén: una metáfora sobre el origen y la caída, un espacio mítico en el que extrañamente coinciden el paraíso y el infierno.

Inés Arredondo supo que crear era cosa de locos y, no obstante, se abandonó furiosamente a la creación literaria porque sabía que sólo allí encontraría la paz de la razón. Entregada al difícil juego de reconstruirse por medio del lenguaje, produjo algunas de las mejores páginas que hayan podido escribirse en nuestras letras. Cuentos terribles por su excesiva perfección. Textos diversos, siempre punzantes y sinceros, escritos al borde del precipicio, que producen vértigo al tiempo que seducen, que iluminan hasta enceguecer. El mejor reconocimiento que podemos hacer a esta extraordinaria escritora universal es leerla hoy, mañana, siempre. 
CITAM Derechos Reservados.

La reproducción total o parcial de este artículo se podrá hacer si el ITAM otorga la autorización previamente por escrito. 